\title{
QUEIMADURA: EFEITOS PSICOSSOCIAIS NAS VÍTIMAS
}

\section{CATEGORIA: EPIDEMIOLOGIA/ SAÚDE COLETIVA}

\section{INSTITUIÇÃO: CENTRO UNIVERSITÁRIO SÃO CAMILO}

\section{AUTORES:}

Fé, DSM ${ }^{2}$ : Rua Tenente Azevedo, 104 - apto 211 A, CEP 01528-020, Cambuci. (11) 97652-2648. dianasmourafe@gmail.com

Germino, $C^{2}$

Mendonça, IB ${ }^{2}$

\section{ORIENTADORA:}

Manso, MEG ${ }^{1}$

1 Docente da Faculdade de Medicina do Centro Universitário São Camilo

2 Discentes da Faculdade de Medicina do Centro Universitário São Camilo 
QUEIMADURA: EFEITOS PSICOSSOCIAIS NAS VÍTIMAS

\section{CATEGORIA: EPIDEMIOLOGIA}

DESCRITORES: "QUEIMADURAS", "ESTIGMA SOCIAL", "DESEJABILIDADE SOCIAL", "AUTOIMAGEM" 


\section{RESUMO:}

INTRODUÇÃO: Queimaduras são acidentes comuns que, apesar de notável progresso no seu tratamento, ainda apresentam prognóstico incerto, envolvendo fatores biológicos, psíquicos e socioculturais. No âmbito psicossocial, a queimadura promove alterações permanentes e capazes de modificar a percepção da vítima sobre seu corpo e imagem, além de trazer repercussões à sua inserção social.

OBJETIVOS: Analisar como um grupo de pessoas vivenciaram o acidente de queimaduras, como veem sua autoimagem após o acidente e a influência deste no meio social.

MÉTODOS: Trata-se de um estudo qualitativo, realizado com 30 pacientes do Ambulatório de Queimados do Hospital Geral Vila Penteado, cidade de São Paulo, durante o mês de julho de 2017. Os pesquisadores desenvolveram um questionário composto por questões objetivas tais como sexo, idade, tipo de queimadura, seguido por um roteiro de perguntas norteadoras que guiaram a entrevista semi-estruturada. Este instrumento foi aprovado pelo CEPE da instituição de ensino e pelo hospital. As entrevistas foram gravadas e posteriormente transcritas pelos pesquisadores. Para confecção do corpus de analise, utilizou-se como auxiliar o software AtlasT.i 8.0®.

RESULTADOS: A idade dos entrevistados variou entre 18 e 82 anos, com predomínio do sexo masculino e queimaduras de $2^{\circ}$ grau. A partir da análise das entrevistas foram elaborados três diagramas que expressam as inter-relações entre como os acidentados explicam seu acidente, como vivenciam o estar queimado e sequelas e como sentem que o grupo social os vê. Muitos relacionam seu acidente como predestinação e demonstram sentimento de negação e dificuldade de aceitação de seus corpos agora com cicatrizes. Relatam ainda que há uma grande rejeição social e um estigma com relação a suas marcas, com desenvolvimento de depressão e de tentativas suicidas.

CONCLUSÃO: As lesões da queimadura promovem alterações físicas e psíquicas, as quais podem manifestar diversas reações frente ao tratamento e à nova realidade na qual se inserem. Depressão, suicídio, negação da própria imagem, culpabilização, apego religioso e exclusão social são aspectos que predominaram nos discursos. Assim pode-se inferir que o estigma por trás das queimaduras se faz muito presente. DESCRITORES: queimaduras, estigma social, desejabilidade social, autoimagem 


\section{QUEIMADURA: EFEITOS PSICOSSOCIAIS NAS VÍTIMAS}

\section{INTRODUÇÃO}

A pele corresponde a todo o revestimento externo do corpo e, devido a sua ampla extensão, é o maior órgão humano, respondendo a aproximadamente $15 \%$ da massa corpórea.

Segundo o livro Suporte Básico de Vida ${ }^{1}$ a definição de queimaduras consiste em lesões de tecidos, que são consequência da transferência de energia de uma fonte para o corpo, sendo estas fontes agentes térmicos, elétricos, radioativos, ou químicos, e que variam de tamanho de área afetada.

Atualmente, dentre os acidentes mais comuns, estão envolvidos casos de queimaduras, visto que diversos instrumentos com potencial traumático são manuseados ou, simplesmente, estão presentes no cotidiano.

Costuma-se dividir cinco agentes passíveis causadores do trauma: os térmicos (como fogos, superfícies superaquecidas), químicos (como produtos a base de ácidos), mecânicos (atrito de superfícies), biológicos (animais principalmente águaviva e medusa em regiões litorâneas, mas também lagarta-de-fogo, algumas plantas específicas, etc), radiação (solar, raio X, nuclear, entre outros) e eletricidade (correntes elétricas e raios) $)^{2}$. Além destes fatores de traumas acidentais de queimaduras não se pode ignorar o potencial intencional, em que diversas tentativas mal sucedidas de suicídio também geram queimaduras e lesões traumáticas aos pacientes ${ }^{3}$.

Estes objetos e substâncias podem causar pequenas queimaduras, facilmente tratadas, ou lesões de um grau mais elevado trazendo consequências irreversíveis ao paciente. Deste modo, considerando a gravidade dos casos e consequências destes traumas, surgiu necessidade de pesquisar sobre os aspectos psicológicos associados, mediante a importância que os mesmos apresentam para a clínica.

O tratamento do paciente queimado evoluiu muito principalmente a partir da Segunda Guerra Mundial. Ao longo do tempo houve um grande progresso no tratamento o que trouxe a diminuição da mortalidade do paciente vítima de 
queimadura além da melhora da qualidade de vida. Porém, mesmo com todos os avanços, o prognóstico no tratamento continua sendo, muitas vezes, imprevisível, pois a evolução do paciente é complexa e depende de múltiplos fatores tais como o atendimento da equipe multidisciplinar, a qualidade do centro de atendimento, além da resposta individual do paciente ${ }^{4}$. O que implica não somente a resposta do organismo físico, mas o ser humano como um todo, sua interpretação de vida, formas de encarar a situação, seus valores, pensamentos e sentimentos.

As cicatrizes podem ocasionar dificuldades de mobilidade, contraturas, perda de sensibilidade e prurido. Psicologicamente, os pacientes queimados podem sentir seus corpos vergonhosos, angustiantes, não familiares, vulneráveis e restritos ${ }^{5}$. Dessa forma, é evidente o impacto das lesões oriundas da queimadura no âmbito psicossocial dos pacientes, visto que a mesma promove alterações definitivas e, por vezes, capazes de modificar a percepção da vítima sobre seu próprio corpo e imagem perante a sociedade em que se encontra inserida.

As queimaduras são um grande problema de saúde pública em relação à gravidade de suas lesões e sequelas físicas (motoras e estéticas) que são capazes de gerar, mas também quanto às demais sequelas que marcam o paciente queimado de outras maneiras ${ }^{6}$ as quais serão expostas no artigo em questão.

O objetivo deste artigo é relacionar: queimadura, causalidade, autoimagem do paciente e a exclusão social que está suscetível.

\section{MÉTODO}

Trata-se de um estudo primário, qualitativo, em que foi realizada uma pesquisa com 30 pacientes do Ambulatório do Hospital Geral Vila Penteado (hospital público localizado na cidade de São Paulo referência no tratamento e atendimento à vítima de queimaduras).

O grupo de estudo da pesquisa abarcou os pacientes com idade superior ou igual a 18 anos sem déficit cognitivo. Não houve seleção de etnia, classe social, orientação sexual, grau de escolaridade ou crença durante a realização da pesquisa. Foram excluídos apenas os pacientes com idade inferior a 18 anos, e/ou que não estavam 
em plena consciência de seus atos e os que por qualquer motivo optaram por abandonar a entrevista.

Após o paciente ler e assinar o TCLE, foram coletados dados pessoais básicos: identidade sexual, etnia, profissão atual, estado civil, ano do acidente, grau de extensão da lesão. Após essa sequência de perguntas objetivas iniciou-se uma conversa com o paciente, realizando uma entrevista semiestruturada que foi gravada sob consentimento do paciente. O questionário utilizado para a entrevista foi previamente elaborado pelos pesquisadores e aprovado pelo Comitê de Ética em Pesquisa.

Após o término das entrevistas, as gravações foram transcritas para um documento digital e passaram por uma análise a fim de identificar o discurso do sujeito coletivo, mediante o software Quali-quantitativo (Atlas Ti $8.0 \circledR$ ).

A pesquisa foi realizada durante o mês de julho de 2017, após a aprovação do Comitê de Ética em Pesquisa do Centro Universitário São Camilo, número de registro: 62728316.2 .0000 .0062 .

\section{RESULTADOS E DISCUSSÃO}

Observou-se uma variação de idade de 18 a 82 anos, com predomínio do gênero masculino $(61,3 \%)$. As queimaduras de $2^{\circ}$ grau foram as mais frequentes, com $50 \%$ dos casos, como podemos perceber no QUADRO 1.

\begin{tabular}{l|l|l} 
GRAU DA QUEIMADURA & $\mathrm{N}$ & $\%$ \\
\hline 1 ㅇ & 1 & $3,3 \%$ \\
\hline 1ㅇ e 2ㅇ & 1 & $3,3 \%$ \\
\hline 2 ㅇ & 15 & $50 \%$ \\
\hline 2 ㅇ e 3 & 8 & $26,6 \%$ \\
\hline 3 o & 3 & $10 \%$ \\
\hline Indeterminado & 2 & $6,6 \%$ \\
\hline Total & 30 & $100 \%$
\end{tabular}

QUADRO 1: Grau de queimadura apresentado pelos pacientes. As porcentagens encontram-se aproximadas. 
A predominância do gênero masculino está presente em outros trabalhos, e está relacionada ao emprego dos homens com maior exposição de riscos como eletricista, mecânicos, entre outros. Enquanto as queimaduras das mulheres estão majoritariamente associadas à atividades domésticas ${ }^{7}$. Esta tendência de maior predomínio do sexo masculino não é uma realidade apenas brasileira, outros países do mundo também possuem o mesmo cenário.

A média de idade foi de 38,6 anos, e a mediana foi de 39 anos o que também se relaciona com a literatura de outros trabalhos que demonstram que a faixa etária mais atingida como a de 20-39 anos. Esta faixa etária corresponde a população economicamente ativa, dessa forma, esse fato demonstra o potencial de desestruturação que a queimadura é capaz de promover na ordem econômica e social, uma vez que esses indivíduos são, majoritariamente, os responsáveis pela fonte de renda familiar ${ }^{8}$.

É válido ressaltar que a porcentagem de superfície corporal queimada predominante $(36,6 \%$ dos pacientes) consiste na faixa de variação de 1 a $5 \%$ (11 pacientes), QUADRO 2.

\begin{tabular}{l|l|l} 
SUPERFÍCIE CORPORAL QUEIMADA & $\mathrm{n}$ & $\%$ \\
\hline$<1 \%$ & 3 & $10 \%$ \\
\hline $1-5 \%$ & 11 & $36,6 \%$ \\
\hline $6-10 \%$ & 5 & $16,6 \%$ \\
\hline $11-15 \%$ & 1 & $3,3 \%$ \\
\hline $16-20 \%$ & 2 & $6,6 \%$ \\
\hline $21-25 \%$ & - & - \\
\hline $26-30 \%$ & 3 & $10 \%$ \\
\hline $31-35 \%$ & 1 & $3,3 \%$ \\
\hline $36-40 \%$ & 1 & $3,3 \%$ \\
\hline $41-45 \%$ & 1 & $3,3 \%$ \\
\hline Não determinado & 2 & $6,6 \%$ \\
\hline Total & 30 & $100 \%$
\end{tabular}

QUADRO 2: Superfície corporal afetada pela queimadura. As porcentagens encontram-se aproximadas.

Ao analisar os agentes causais das queimaduras observou-se que $27 \%$ foram causados por explosão, $23 \%$ por escaldo a vapor, $13 \%$ por álcool, $13 \%$ por escaldo a 
óleo, $10 \%$ por eletricidade, $3 \%$ por acidente automobilístico, 3\% por explosão a gás e 7\% não foi informado, podemos observar essas informações no QUADRO 3.

\begin{tabular}{l|l|l} 
AGENTE CAUSAL & $\mathrm{n}$ & $\%$ \\
\hline Acidente automobilístico & 1 & $3,3 \%$ \\
\hline Acidente elétrico & 3 & $10 \%$ \\
\hline Água do radiador & 1 & $3,3 \%$ \\
\hline Álcool & 4 & $13,3 \%$ \\
\hline Escaldo & 9 & $30 \%$ \\
\hline Explosão & 3 & $10 \%$ \\
\hline Fogo & 6 & $20 \%$ \\
\hline Gasolina & 1 & $3,3 \%$ \\
\hline Não informado & 2 & $6,6 \%$ \\
\hline Total & 30 & $100 \%$
\end{tabular}

QUADRO 3: Porcentagem de pacientes por agentes causais da queimadura. As porcentagens encontram-se aproximadas.

Infelizmente, nem todos os prontuários possuíam as informações completas sobre os procedimentos que foram realizados nos pacientes, então, a partir dos dados que pudemos colher mediante essa restrição, temos: metade $(50 \%)$ dos pacientes precisaram de correção cirúrgica, sendo a modalidade mais frequente, o debridamento. Em contraposição, 36,67\% dos pacientes (11 indivíduos) não necessitaram de internação, e a mesma quantidade $(36,67 \%)$ fizeram acompanhamento com a psicóloga.

A partir do software Atlas Ti $8.0 \AA$, foram elaborados 3 diagramas com os seguintes tópicos: causalidade, autoimagem e exclusão social, tais diagramas constroem inter-relações entre palavras dos diversos discursos dos pacientes e as separam em grupos e subgrupos. A seguir serão analisados os diagramas isoladamente. 
Para se relacionar à causa da lesão dos pacientes, há duas palavras de grande impacto: predestinação, a qual se divide em outras duas: sobrenatural e predestinação, a outra é culpabilização, que se divide em estresse e culpa.

A palavra predestinação relacionada com sobrenatural apresenta as seguintes ramificações: Deus, livramento de Deus, surreal, sonho, pressentimento ruim e propósito de Deus. Já a palavra predestinação, também relacionada diretamente à predestinação, que se expressa em "tinha que ser eu". Em culpabilização, há a palavra estresse e culpa a qual se divide em: tinha que ser eu, aprendizagem, aprendizado, culpa, provação, exemplo e desejo de morte.

Com base na descrição do diagrama de causalidade pode-se inferir que dentre os entrevistados, temos uma divisão em dois grandes grupos com relação a causalidade, são eles: sobrenatural e culpabilização. Os pacientes pertencentes ao grupo do sobrenatural acreditam que o acidente, era algo inevitável, pois estavam predestinados a isso. É interessante notar que há uma grande conotação religiosa no discurso desses pacientes o que permite dizer que a religião tem um impacto, por vezes, extremamente benéfico no processo de reabilitação, entendimento do acidente e aceitação por parte das vítimas. Pois, estes acreditam que a queimadura faz parte de um propósito maior no plano de suas vidas e se apoiam na fé como sustentação neste momento de dificuldade.

Segundo Cerqueira-santos, Koller e Pereira9 "A religião surge, então, como resposta à necessidade de explicar e justificar fatos naturais e não-controláveis como a morte, e, às vezes, a doença". De acordo com Mello e Oliveira10 "No Brasil, a maioria das pessoas acredita na ação do sagrado na prevenção e na cura de enfermidades e os problemas de saúde estão entre as principais razões que levam as pessoas a procurarem ajuda religiosa no país. Dessa forma, os grupos religiosos podem funcionar como uma intensa rede social de apoio, influenciando diretamente na tolerância da comunidade para com a pessoa em sofrimento psíquico, o que poderá repercutir na sensação de acolhimento e bem-estar por parte do enfermo".

Estes sentimentos estão retratados em diversos trechos das entrevistas, como nos exemplos:

"Se não fosse eu não crer em Deus eu não taria.....Não, Se não fosse Deus eu não estaria aqui." (P.A.) 
"Eu sei que tudo o que acontece é permissão de Deus nas nossas vidas, não cai um fio de cabelo sem que Deus não Ihe permita. Muitas vezes Deus Ihe permite acontecer várias coisas, mas que ele não quer, muitas coisas acontecem por certas atitudes nossas também, né?" (P.B.)

"Depois pensando atrás eu penso assim: não, e o livramento que Deus me deu de morte né, não quebrei o braço, não quebrei braço, não quebrei perna, não fiquei cega do meu olho que Deus me deu livramento pra mim não ficar cega do olho, não atingiu minhas vistas, graças a Deus." (P.C.)

"Eu acredito que Deus tem um propósito pra cada um de nós” (P.D.)

"Ah.. acho que foi livramento de Deus primeiramente" (P.E)

De acordo com Manso ${ }^{11}$ "Alguns autores associam ainda a visão da enfermidade enquanto expiação com o pensamento cristão ocidental, o qual relaciona a doença a uma punição ou a redenção de pecados cometidos, o que é visto nos relatos dos pacientes.

Esses pacientes acreditam que, em certo grau, estavam predestinados a isso. Porém, há um subgrupo que crê que o acidente representou uma espécie de provação (a religião se mostra bem evidente novamente nesse quesito), um aprendizado. $\mathrm{E}$, apesar de não citarem diretamente o nome de Deus, alguma entidade religiosa, o destino, entre outros, este pensamento de predestinação se faz presente, como nos trechos:

"Ai moça, é um horror, porque você olha e não tinha como evitar, eu não podia adivinhar que o menino ia esbarrar no balde de óleo bem quando eu passasse. Foi, tipo, uma coincidência. Assim, surreal. Aconteceu... e foi bem no dia que eu deixei a minha mochila na parte de baixo, e eu sempre deixo na parte de cima. Eu falei: "é uma coisa, não é possível"(P.G)

"Foi uma coisa que tinha que acontecer. Foi um acontecimento que tinha que acontecer. Eu acho até que eu tinha que ter passado "(P.H)

" Tinha que acontecer né, não adianta, e tinha que ser comigo" (P.I) 
"Eu acho que o que acontece pra você é porque tem que acontecer. Então o que a gente tem que passar a gente tem que passar né" (P.J)

Existe o grupo que se culpa pelo que aconteceu, considerando-se responsáveis pelo ocorrido, exemplificado no relato a baixo:

"Não era pra mim já não ir, parecia que algo já falava que pra mim já não ir, ai quando eu sofri o acidente eu tive certeza que era pra mim não ir e ai eu tive um pouco de culpa" (P.F)

Segundo Manso 11 "Estudar a causalidade das doenças do ponto de vista do adoecido permite entender o significado associado às questões do tipo "por que eu" e "por que agora", relacionando o adoecer a visão de mundo e à ordem social".

\section{DIAGRAMA: AUTOIMAGEM}

As queimaduras são capazes de comprometer a autoimagem do paciente, pois atinge a identidade do indivíduo, uma vez que a autoimagem está altamente ligada a aparência, principalmente facial ${ }^{8}$.

A autoimagem abrange a forma como as vítimas interagem com a sociedade e consigo mesmas após modificações estéticas que podem ser devastadoras, juntamente a isso tem-se que analisar como esses pacientes se comportam e como são tratados pelas pessoas ao seu redor, visto que muitos acabam sendo julgados e estigmatizados como anomalias o que promove exclusão social dos pacientes vítimas de queimaduras.

Dos diagramas fornecidos pelo software, o mais complexo foi o da autoimagem, visto que foram gerados 4 grupos determinados pelas palavras: superação, rejeição, vergonha e depressão, respectivamente. Porém, esses grupos apresentam uma vasta correlação o que torna a análise rica em detalhes.

Os grupos rejeição, vergonha e depressão tem uma extensa correlação entre seus subgrupos. A rejeição está intimamente relacionada às mudanças físicas que a queimadura provocou nos pacientes, ou seja, os pacientes alegam não se reconhecerem (se dizem muito feios, que há um desfalque em sua aparência) ou apresentarem um estigma corporal. Esse estigma se faz presente de diversas 
maneiras, tais como: os pacientes referem que as pessoas desviam o olhar deles, suas cicatrizes despertam curiosidade e inúmeros questionamentos das pessoas que os cercam, eles se sentem marcados, com o corpo deformado. Muitos evitam usar roupas curtas, olhar-se no espelho, sentem-se tristes e com vergonha o que impacta diretamente na autoestima das vítimas. E, neste ponto compreendemos a forte relação existente entre auto-imagem e interação social.

Goffman ${ }^{12}$ afirma que as pessoas que possuem marcas que levam ao estigma são colocadas em determinadas categorias, como qualquer outra marca que estereotipe um indivíduo, sofre de uma incerteza: qual categoria em que ela será colocada e se essa categoria é favorável. Outrossim, afirma também que quando em contato com indivíduos que não possuem essa "marca", sente-se em exposição.

Esta rejeição é ainda maior quando a área queimada acomete regiões da face, pois é uma região exposta em tempo integral e é a parte corpórea que mais define o indivíduo. "A face é o ponto central das características físicas do ser humano. Por isso, as queimaduras nessa região são sempre devastadoras, com graves repercussões físicas, emocionais, psicológicas, sociais e profissionais ${ }^{13 " .}$.

Estas falas de rejeição do próprio corpo foi algo muito presente em diversos discursos, como por exemplo, segundo um depoimento, com o "corpo podre". A rejeição se relaciona muito com o estigma corporal, pois os pacientes referem que apresentam muita resistência com relação a sua nova fisionomia, ou seja, há uma grande dificuldade de aceitação. Eles se sentem deformados, afetados por algo que os marcou e que, como dito por eles, "nunca vai sair". Os pacientes têm dificuldade de se olhar no espelho e encarar sua nova fisionomia, demonstrando uma dificuldade de aceitação consigo mesmos. Além da dificuldade de usar roupas curtas, que mostra a rejeição social também, fazendo com que os pacientes criem maneiras de esconder ou evitar de expor as cicatrizes.

Este sentimento é evidente nos trechos:

"Você vai falar assim: eu não sou mais o mesmo, e não é. Não adianta falar que é porque na estética não é mais o mesmo nunca mais. Só que ai a gente vai se acostumando, entendeu. É pesado." (P.K.) 
"O acidente representa... um desfalque no seu corpo, é uma marca que vai ficar pra sempre, que nunca vai sair. Entendeu? Ao mesmo tempo que eu senti ódio, eu senti horror, sabe que você olha e você não acredita?" (P.L)

"Cê, cê (você) é perfeita de repente se tá com o corpo todo deformado." (P.M)

"Até hoje eu não me olho no espelho, eu não me vejo, eu não coloco nada curto, nada.. eu não tenho mais vaidade. Eu não tenho mais nada." (P.A.)

"Eu fico olhando assim e fico meu Deus que negócio horrível, eu fico no espelho assim e eu já saio, porque é muito feio, eu acho. Porque elas ficaram aquelas que enrugou um pouco sabe?" (P.N.)

"Quando eu olho no espelho principalmente a lateral assim, é.. sei lá, dá uma tristeza muito grande apesar de não ter perdido mobilidade, não ter perdido nada, ter sensibilidade tudo normal, mas a gente sente assim um pouco de deformidade né?, eu lembro como eu era antes, eu vejo a foto de como eu era antes e vejo no espelho como eu sou agora dá uma tristeza muito grande." (P.O.)

Goffman ${ }^{12}$ afirma que o estigma se relaciona com símbolos e signos, como se pode perceber na seguinte passagem:

"Alguns signos que trazem informação social, cuja presença, inicialmente, se deve a outras razões, têm apenas uma função informativa superficial. Há símbolos de estigma que nos dão exemplos desse ponto: as marcas no pulso que revelam que um indivíduo tentou o suicídio; as marcas no braço do viciado em drogas; os punhos algemados dos prisioneiros em trânsito; ou mulheres que aparecem em público com um olho roxo como o sugere um autor que escreve sobre prostituição."

A partir do trecho de Goffman refletimos que a queimadura também produz um símbolo no paciente que, a partir daquele momento, possui uma nova marca e consequentemente um estigma antes inexistente que gerará novos sentimentos, questionamentos, interpretações e julgamentos por si próprio e pela sociedade em que está inserido.

Manso ${ }^{10}$ também afirma que pacientes ainda sofrem com estigma de outros indivíduos, são vistos como leprosos, como se a doença que os acomete fosse transmissível. Há o relato de pacientes que veem a marca da queimadura como uma chaga, e se refere como "lepra", como se os outros indivíduos fossem acreditar que a marca que possui seja contaminante.

"Eu não gosto de sair de bermuda sem meia, se eu coloco uma bermuda, assim, vou colocar assim, sem a malha, eu ponho só a meia, aí fica marcado, a pessoa olha pra sua perna com nojo, né? 
Esse cara tá empesteado, tá com alguma coisa, é lepra, é... ele não sabe o que aconteceu e a pessoa se afasta." (P.W)

De acordo com Goffman ${ }^{12}$, o autor exemplifica o caso de um médico que vê um paciente com a doença de Huntington, esse identifica a patologia, mas o indivíduo que não o conhece, estigmatiza o outro, por esse não ser o estereótipo do "normal". Da mesma forma, uma pessoa acometida por queimadura sofre, pois ninguém sabe o que se passou com ela, apenas reconhece que ela possui algo de "diferente", que "foge da normalidade". Este sentimento está ilustrado na fala:

"Eu tenho vergonha de entrar na piscina, porque eu não sei o que as pessoas pensam né? " (P.Q.)

Goffman ${ }^{12}$ afirma que o indivíduo que possui "visibilidade" em sua identidade social, possui as seguintes características: possibilidade de ser reconhecido (conhecimento prévio do que faz o indivíduo ser estigmatizado), intrusibilidade (quando o outro indivíduo é capaz de questionar sobre o que está relacionado no fator de seu estigma) e possuir foco de percepção, desqualificando o portador de um determinado estigma. Isso vai depender de diversos fatores no paciente com sequela de queimadura, mas no seu discurso, podemos perceber que possui incômodo quando com medo de se mostrar, ao sentir dificuldade de ir à praia, utilizar roupas mais curtas, pois há exposição do corpo, possuindo a possibilidade de ser reconhecido, a chance de intrusibilidade do outro e pode ser foco de percepção.

Na categoria vergonha também expressa basicamente os apontamentos dos parágrafos anteriores, visto que implica em tristeza devido as marcas das lesões, os pacientes tentam se esconder, pois se sentem feios, envergonhados e afetados pela queimadura de uma forma muito mais profunda que somente fisicamente.

"É eu mesma que me acho feia, eu que me acho feia, o braço. Não é o que os outros vão achar, é por mim mesmo, meu braço era tão bonitinho" (P.R.)

"Eu procuro assim não olhar pras minhas pernas, porque eu olho eu sinto repulsa. Muito feio, Eu não gosto entendeu. Eu procuro usar roupa comprida. Eu procuro cobrir sabe? Eu não gosto, eu acho muito feio." (P.N) 
A depressão, por sua vez, está muito ligada a tristeza que os pacientes referem, ao sentimento de vergonha do próprio corpo o que os faz, por vezes, perder a vaidade e a autoestima. Referem-se desanimados, ansiosos, com medo.

"É difícil, tem que estar com o psicológico preparado porque tem chance de ficar até com problema, ficar alucinado porque não é fácil. É muito difícil, sabe. É doloroso e o sofrimento não é na hora que queima, é depois, no hospital, o tratamento, na hora de curativo, dói tudo e o psicológico depois de ver aquele monte de cicatriz, de marca. (P.K)

"Ah, se sente bem, a gente se sente bem pra baixo. É um negócio difícil. Eu me senti bem desanimado, tipo assim, querendo achar um motivo de uma culpa, mas porque que eu estou assim. Mas você vai fazer o que, aconteceu. Pelo menos não queimou o rosto que é pior." (P.A)

Algo que chamou bastante a atenção no diagrama foi a palavra dependência, ou seja, devido as lesões e as limitações que elas geram, os pacientes acabam por depender de amigos e familiares para realizar tarefas corriqueiras o que os faz sentirse impotentes e dependentes. Os pacientes acabam por perder a autoconfiança e a motivação para buscar um avanço ou uma adaptação ao tratamento e a nova condição de vida na qual está inserido. Outrossim, o cuidador também se sente na responsabilidade de cuidar do paciente, como Goffman ${ }^{12}$ afirma.

Este cenário demonstra que apesar da qualidade do atendimento que resulta na alta hospitalar, as sequelas do acidente fazem com que os pacientes vítimas de queimaduras retornem para suas casas inseridos em uma realidade diferente, em que surge um novo desafio de adaptação na tentativa de retomar a vida e suas atividades diárias ${ }^{14}$.

Dessa forma, as queimaduras também trouxeram aos pacientes limitações em suas atividades cotidianas, isto resultou, muitas vezes, na dependência em outras pessoas para realizar ações simples, essa dependência também foi citada inúmeras vezes como algo que potencializa o sentimento de tristeza e impotência.

"Eu fiquei dependendo dos outros pra ir no banheiro, pra comer, pra vestir uma roupa né? e assim parcialmente destruiu minha vida porque eu fiquei dependendo das outras pessoas uma coisa que eu nunca fui, fui aprender a depender dos outros." (P.N)

"Eu odeio depender dos outros até da minha filha eu não gosto de ficar pedindo favor, tomar banho, trocar de roupa eu tenho que ficar "vamo gente me troca que eu tenho uma reunião, tenho que sair" isso que é o chato da história." (P.R.) 
"Tudo que eu vou fazer depende de alguém hoje, tudo que eu vou fazer depende de alguém" (P.S.)

"Eu não conseguia segurar um copo, dependia dele colocava na minha boca então eu pensava 'olha o trabalho que eu tô dando pra uma criança de 12 anos' foi então que eu tomei a decisão, de tentar suicídio né" (P.A.)

Este quadro mostra a necessidade integral e interdisciplinar do atendimento ao paciente queimado, com uma equipe competente atuando em todas as fases de reabilitação para minimizar as deficiências motoras e também psicológicas, visando a melhoria da qualidade de vida do paciente ${ }^{6}$.

Muitas vezes, a insatisfação é tão grande que traz o sentimento de terminalidade da vida. Foi notado na análise dos depoimentos este aspecto que consiste no pensamento e, até mesmo, em práticas suicidas pelos pacientes, podese notar tais aspectos nos seguintes trechos retirados das entrevistas:

"Tudo, mudou tudo. No começo eu só pensava em suicídio. Eu não andava, eu não andava mais, eu não conseguia, porque queimou praticamente o corpo quase todo, eu não tinha expectativa de vida. Aí o marido deixou, eu não andava ainda né? Pediu divórcio pra não cuidar. Então eu passei uma depressão muito severa mesmo a ponto de tentar o suicídio três vezes" (P.A)

"Na verdade eu desejei até morrer pra você ter ideia, mas não chegou minha época. Então estamos ai lutando pra chegar nos 100\% ." (P.X)

Não há consenso na literatura de que as pessoas que sofreram queimaduras podem apresentar inclinação maior para o suicídio ${ }^{15}$, porém é fato que a queimadura representa, socialmente, muito mais do que a ameaça de uma "doença cutânea" crônica - ela afeta drasticamente a identidade da pessoa queimada, como consequência do estigma que ainda existe em nossa sociedade ${ }^{15}$.

\section{DIAGRAMA: EXCLUSÃO SOCIAL}

Altamente relacionado com o tópico anterior "autoimagem" se encontra o tópico exclusão social. A falta de aceitação consigo e seu corpo gera situações de baixa autoestima e falta de autoconfiança. Este cenário se intensifica com o medo do 
julgamento alheio, com a percepção dos olhares curiosos, questionamentos, surgindo um sentimento de vergonha de si. Esta realidade resulta em diversas maneiras do paciente de esconder-se de si próprio e da sociedade que o cerca, evitando o convívio interpessoal, o que intensifica o sentimento de tristeza e depressão.

A partir da palavra exclusão, surgem três novas se relacionando: vergonha, rejeição e exclusão.

A palavra "vergonha" se relaciona com as seguintes expressões: as pessoas olham, prefiro me esconder, vergonha, evita entrar na piscina, não depende de mim, negação e nojo.

Já a palavra "rejeição": as pessoas olham, nojo, divórcio, perguntam, as pessoas veem como um problema, marido não quer cuidar, as pessoas olham demais, as pessoas não respeitam e empesteado.

E a palavra "exclusão" está relacionada com: as pessoas não respeitam, empesteado, nojo, olham diferente, inexplicável, preconceito, lepra, menosprezo, falam que é frescura, tantos nãos e se sente ET.

A vergonha está relacionada ao sentimento desses pacientes com relação a sociedade que o cerca, ou seja, como eles se veem perante ela e como ela os vê. Esses pacientes referem vergonha porque as pessoas olham. Constrangidos, evitam entrar na piscina e tentam se esconder.

É importante destacar que a exclusão social começa dentro do próprio hospital, devido ao caráter limitante da queimadura. Ressaltando-se que o tempo de internação médio de vítimas de queimaduras é de muitos dias o que acaba interferindo também no convívio social. Segundo Fonseca Filho et. Al ${ }^{16}$ "O período estimado é de 24 dias, prolongando para 40 dias dependendo do grau da lesão. Esta exclusão de muitos dias representa um grande impacto psicossocial, visto que o paciente se ausenta do trabalho e do convívio da família por um longo período, ficando isolado e ansioso para o retorno social".

Chama atenção o uso da palavra "nojo", alguns relatam acreditar que as pessoas sentem nojo deles, dizem que é algo que não depende deles, pois não podem controlar os julgamentos e estigmas que a sociedade os impõem. 
"É no começo eles olhavam com nojo né. [...] a gente é uma carne podre, fedia muito quando foi feito o enxerto que eu fui pra casa, fedia muito então o pessoal acaba ficando com nojo" (P.U.)

"Já, onde eu chego as pessoas olham pra minha cara. Falam: meu Deus, seu rosto" (P.V.)

A rejeição está relacionada novamente com o nojo, um paciente chega a referir que sente que seu corpo está "empesteado". As vítimas alegam que os outros encaram suas cicatrizes e lesões decorrentes do acidente como um problema, relatam que as pessoas não os respeitam, olham demais.

"Desvia o olhar pra você, dá essa sensação. era assim quando eu entrava no mercado, quando saia na rua, as vezes, até os vizinhos, né? Quando iam me visitar, as vezes parece que você chama atenção, né?" (P.W)

"Eu cheguei a ir pra praia até com a malha compressiva, virei a atração da praia, onde eu passava todo mundo olhava." (P.O)

A exclusão, por sua vez, correlaciona-se com a rejeição, visto que os pacientes dizem que as pessoas não os respeitam, sentem nojo. Os pacientes referem-se menosprezados, vítimas de preconceito. Nesse subgrupo há 3 palavras que são de grande impacto e que chamam muito a atenção: "lepra", "empesteado" e "sente-se ET", ou seja, é claro a visão depreciativa que os pacientes fazem de sua imagem o que reflete a negatividade com que enxergam sua melhora e adaptação.

"As pessoas ficam olhando pra gente, a gente se sente meio sabe.. meio ET né? Conforme vai passando o tratamento, vai voltando ao normal tudo direitinho a gente acaba se acostumando, mas até hoje eu tô fazendo terapia pra ficar em paz com a cicatriz" (P.T.)

A exclusão social muitas vezes não é só devido à aparência física, mas também devido aos julgamentos da situação por parte da sociedade, que, muitas vezes por falta de conhecimento ou falta de empatia não compreende os medos, sentimentos e 
atitudes da vítima de queimadura. A fala que se segue é o relato de uma paciente vítima de um acidente de explosão da panela de pressão em seu ambiente de trabalho, em que trabalhava como cozinheira:

"As pessoas não tem respeito com as sequelas com os traumas que eu tenho de cozinha, não respeitam eu não querer fazer nada na cozinha, porque eu não quero ficar lá." (P.N)

O que nos surpreende é que de acordo com Goffman ${ }^{12}$ "Em primeiro lugar as pessoas íntimas podem se tornar aquelas em relação quais ele mais se preocupa em esconder algo vergonhosa", logo, o paciente queimado pode se sentir mais envergonhado com pessoas mais próximas, como no caso de mulheres que sentem dificuldade de se relacionar com seus parceiros. Podemos evidenciar isso no seguinte depoimento:

"Eu não consigo ter relacionamentos com ninguém. Afetou...não.. eu até casei, indo pra igreja casei, mas não consegui me despir pro esposo né então." (P.A)

\section{CONSIDERAÇÕES GERAIS}

As lesões oriundas da queimadura promovem alterações físicas e psíquicas nos pacientes os quais podem manifestar diversas reações frente ao tratamento e a nova realidade que se inserem. As lesões acompanham uma gama de sintomas e sentimentos por parte dos pacientes e familiares. Por vezes, os pacientes manifestam sentimento de impotência; para Helman*, em 2009, esta versão, onde se unem sentimentos negativos, emoções, sensações físicas e circunstâncias sociais, econômicas e culturais, corresponderia a uma sobreposição entre as explicações populares, médicas e religiosas para o sofrimento humano, uma metáfora para a sensação de sofrimento pessoal e impotência frente aos fatos da vida ${ }^{11}$.

Foi evidente também o sentimento de culpa expresso por alguns pacientes com relação ao acidente, como se fossem responsáveis pelo fato ocorrido, e o trauma uma consequência de suas atitudes. Entretanto, outros demonstraram um fatalismo inerente ao ocorrido, visto que para eles não havia culpa associada e sim uma força 
maior que os predestinava a passar pelo que passaram, esta força foi diversamente traduzida como Deus, mas também existe outro grupo de pessoas que não nomeava diretamente a Deus, mas encaravam a situação como algo que tinha que acontecer, reflexo da vida, destino, força maior, etc.

Queimaduras não fatais são uma das principais causas de morbidade, incluindo hospitalização prolongada, desfiguração e incapacidade, muitas vezes com o consequente estigma e rejeição ${ }^{15}$. É relevante destacar que pessoas que não se autoculpabilizam e que recebem apoio desenvolvem mecanismos de resiliência, reorganizando sua autoestima e reelaborando-a com o ajuda dos demais o que corrobora para o tratamento e para a melhora clínica dos queimados ${ }^{11}$.

Outro aspecto que foi muito preponderante nos depoimentos consiste na relação entre as alterações físicas que as queimaduras provocam e a mudança na autoestima dos pacientes. Muitos pacientes não aceitam as alterações que ocorreram, não reconhecem seu próprio corpo e negam a si mesmos, criando diversos mecanismos de esconder-se de si próprios. Demonstrando a importância da autoimagem na identidade da pessoa, especialmente quando há o acometimento da face, por ser considerada uma das principais estruturas corporais da identidade. Concomitante a isso tem-se o fato da rejeição social frente a esses pacientes o que os afeta em larga escala e gera sentimentos negativos frente sua autoimagem e seu papel na sociedade.

A exclusão social do paciente vítima de queimadura se traduz em dois momentos: se inicia no período de recuperação que tem uma média de muitos dias de afastamento e depois, no sentimento de vergonha. No momento inicial de exclusão social compulsória o paciente já está aflito e angustiado para o retorno ao trabalho, convívio familiar, e círculo de amigos ${ }^{16}$. Posteriormente o sentimento de vergonha que surge no paciente, associada ao medo do julgamento, ao preconceito, aos olhares curiosos das pessoas que o cerca, aos questionamentos que colocam o paciente em situações desconfortáveis e a falta de compreensão das pessoas faz com que a vítima de queimadura voluntariamente se exclua do convívio social. A exclusão social intensifica ainda mais sentimentos de tristeza e depressão.

Para Canguilhem, "O ser humano faz a sua dor e a sua doença, julgando se estas deixaram de ser normais ou se voltaram a sê-lo"17. Então, cura não implica 
saúde, necessariamente, mas pode significar um novo modo de vida instaurado pela doença. Segundo Mello e Oliveira 10 "O significado de estar doente pode ser entendido como a percepção de sensações e sintomas desagradáveis que, identificados pelo médico ou pelo paciente, também representa a doença como uma construção social e mutável, de acordo com o grupo social e com a identidade cultural. Ou seja, mais do que uma configuração biológica, a doença também é uma realidade social e culturalmente construída e o doente é, sobretudo, um ser social”.

A falta de estudos frente aos aspectos sociais e psíquicos do tema se traduz na falta de atitudes e medidas de melhoria, demonstrando como estamos àquem do tratamento integral ao paciente vítima de queimadura.

\section{REFERÊNCIAS}

1. QUILICI, Ana Paula; TIMERMAN, Sergio. Suporte básico de vida: primeiro atendimento na emergência para profissionais da saúde. Barueri: Manole, 2011.

2. GUSSO, Gustavo; LOPES, José Mauro. (Org.). Tratado de Medicina de Família e Comunidade: princípios, formação e prática. Porto Alegre, Artmed, vol 2 2012, p.2014-2018

3. NESTOR, Alessandra; TURRA, Karyna. Perfil epidemiológico dos pacientes internados vítimas de queimaduras por agentes inflamáveis. Revista Brasileira Queimaduras, Curitiba - PR Brasil, v. 1, n. 13, p.44-50, 2014.

4. GRAGNANI, Alfredo. A pesquisa básica e suas contribuições no tratamento do paciente queimado.Revista Brasileira Queimaduras.,São Paulo - SP Brasil, v. 4, n. 14, p. $251-252,2015$.

5. MARTIN, Lisa et al. Social challenges of visible scarring after severe burn: $A$ qualitative analysis. Burns, [s.I.], v. 43, n. 1, p.76-83, fev. 2017. Elsevier BV. http://dx.doi.org/10.1016/j.burns.2016.07.027.

6. OLIVEIRA, Thayssa de Morais et al. Fisioterapia em grande queimado: relato de caso em centro de tratamento de queimados na Amazônia 
brasileira. Revista Brasileira de Queimaduras., Belém, v. 4, n. 14, p.285-289, 2015.

7. SANTOS JÚNIOR, Rafael Adailton dos et al. Perfil epidemiológico dos pacientes queimados no Hospital de Urgências de Sergipe. Revista Brasileira de Queimaduras, Aracaju - SE - Brasil, v. 4, n. 15, p.251-255, 2016.

8. LIMA, Gabriela Martins de et al. Características dos pacientes que apresentaram queimadura de face em hospital de referência na região amazônica. Revista Brasileira de Queimaduras, Belém - Pa - Brasil, v. 2, n. 14, p.133-139, 2015.

9. CERQUEIRA-SANTOS, Elder; KOLLER, Sílvia Helena; PEREIRA, Maria Teresa Lisboa Nobre. Religião, saúde e cura: um estudo entre neopentecostais. Psicol. cienc. prof., Brasília , v. 24, n. 3, p. 82-91, set. 2004 .Disponível em <http://pepsic.bvsalud.org/scielo.php?script=sci_arttext\&pid=S141498932004000300011\&lng=pt\&nrm=iso>. acessos em 12 jan. 2018.

10. MELLO, Márcio Luiz; OLIVEIRA, Simone Santos. Saúde, religião e cultura: um diálogo a partir das práticas afro-brasileiras. Saúde e Sociedade, [s.I.], v. 22, n. 4, p.1024-1035, dez. 2013. FapUNIFESP (SciELO). http://dx.doi.org/10.1590/s0104-12902013000400006.

11. MANSO, Maria Elisa Gonzalez. SAÚDE E DOENÇA: DO CONTROLE SOBRE OS CORPOS À PERSPECTIVA DO ADOECIDO. São Paulo: Max Limonad, 2015. 232 p.

12. GOFFMAN, Erving. ESTIGMA - NOTAS SOBRE A MANIPULAÇÃO DA IDENTIDADE DETERIORADA. 4. ed.; Ltc, 1981.

13. SOUZA, Sandro Cilindro de; AMORIM, Clébio. Queimadura panfacial - relato de caso. Revista Brasileira de Queimaduras, Salvador - Ba - Brasil, v. 4, n. 14, p.279-284, 2015.

14. NASCIMENTO, Silvana Borges et al. Perfil dos pacientes hospitalizados na unidade de queimados de um hospital de referência de Brasília. Revista Brasileira de Queimaduras, Brasília, v. 3, n. 14, p.211-217, 2015.

15. ARRUDA, Cristiani Nobre de et al. Tentativa de suicídio pós-queimadura: uma experiência humana inscrita na pele. Revista Brasileira de Queimaduras, Fortaleza, p.54-57, 15 jan. 2016. 
16. FONSECA FILHO, Ricardo da et al. Superfície corporal queimada vs. tempo de internação. Análise dos últimos 15 anos. Revista Brasileira de Queimaduras, Rio de Janeiro, Rj Brasil, v. 1, n. 13, p.18-20, 2014.

17. CERQUEIRA-SANTOS, Elder; KOLLER, Sílvia Helena; PEREIRA, Maria Teresa Lisboa Nobre. Religião, Saúde e Cura:: um Estudo entre Neopentecostais. Psicologia CiÊncia e ProfissÃo, Porto Alegre, p.82-91, mar. 2004. 